\title{
Attitudes to Mathematics in Primary School Children
}

\author{
Ann Dowker, ${ }^{1}$ Karina Bennett, ${ }^{2}$ and Louise Smith ${ }^{2}$ \\ ${ }^{1}$ Department of Experimental Psychology, University of Oxford, South Parks Road, Oxford OX1 3UD, UK \\ ${ }^{2}$ St Hilda's College, Cowley Place, Oxford OX4 1DY, UK
}

Correspondence should be addressed to Ann Dowker, ann.dowker@psy.ox.ac.uk

Received 15 June 2012; Revised 24 September 2012; Accepted 8 October 2012

Academic Editor: Helga Krinzinger

Copyright ( 2012 Ann Dowker et al. This is an open access article distributed under the Creative Commons Attribution License, which permits unrestricted use, distribution, and reproduction in any medium, provided the original work is properly cited.

\begin{abstract}
44 Grade 3 children and 45 Grade 5 children from English primary schools were given the British abilities scales basic number skills subtest, and a Mathematics Attitude and Anxiety Questionnaire, using pictorial rating scales to record their Self-rating for maths, Liking for maths, Anxiety about maths, and Unhappiness about poor performance in mathematics. There were few year group differences in attitudes. Boys rated themselves higher than girls, but did not differ significantly in actual performance. Overall, Anxiety was not related to actual performance, but Self-rating was. This relationship between Self-rating and actual performance seemed to develop between Grade 3 and Grade 5. Implications of the findings are discussed.
\end{abstract}

\section{Introduction}

Mathematics depends not only on cognitive abilities but also on emotional factors and attitudes. Several studies have shown that emotional factors may play a large part in mathematical performance, with mathematics anxiety playing a particularly large role [1-3]. One possible reason for the negative association between mathematics anxiety and actual performance is that people who have higher levels of math anxiety are more likely to avoid activities and situations that involve mathematics and, thus, have less practice [4]. Mathematics anxiety might also influence performance more directly, by overloading working memory. For example, Ashcraft and Krause [5] reported that highly math-anxious individuals had significantly lower working memory capacities in mathematics-related tasks than individuals with low levels of mathematics anxiety.

Relationships between mathematics anxiety and performance may also be in the other direction. Poor mathematical attainment may lead to mathematics anxiety, as a result of repeated experiences of failure. Indeed, there is likely to be a vicious circle, where anxiety and performance affect each other negatively. Maloney and Beilock [6] point out that the development of mathematics anxiety is likely to be due both to social factors, such as exposure to teachers who themselves suffer from mathematics anxiety, and to preexisting difficulties in numerical cognition, and that those with initial mathematical difficulties are also likely to be more vulnerable to the negative social influences.

Although mathematics anxiety is a major focus for research, not all attitudes to mathematics are negative, and some people express a strong liking for mathematics [7]. This seems to be particularly the case for mathematically gifted people [8] but is not restricted to them.

Most studies of attitudes to mathematics have involved older children and adults. It is particularly important to investigate the early development of attitudes to mathematics, if we are to understand the relationships between these and actual performance, and if possible to prevent the development of strongly negative attitudes. The relatively few studies that have looked at younger children's attitudes to mathematics have usually shown positive attitudes, with most children claiming to like mathematics ([9-11]). However, studies suggest that attitudes may deteriorate with age, especially through the secondary school period $[9,12,13]$, but also within the primary age group $([10,13])$. One study by Gierl and Bisanz [14] gave somewhat more ambiguous results, indicating an increase in mathematics anxiety but also an increase in liking for maths over the later elementary school years. 
Most studies of secondary school children and adults have been consistent in showing actual performance in mathematics tends to be related positively to liking for mathematics and to high self-ratings in mathematics, and negatively to mathematics anxiety (e.g., [2, 5, 15-17] Lam et al., 2000 ). This is the case not only for advanced mathematics but for basic magnitude comparison skills [18].

Studies of the relationships between attitudes to maths and performance in younger children have not resulted in as clear results as those for older children. Ma and Kishor [17] found that the relationships between attitudes and performance increase with age. Cain-Caston [19] found little relationship between mathematics performance and attitudes in a sample of 8- to 9-year olds. Thomas and Dowker [20] (also see [10]) and Krinzinger et al. [21] found that 6- to 8-year olds' mathematical performance was related to Liking mathematics and to Self-rating of ability in the subject, but not to anxiety. Krinzinger et al. [21] failed to find either longitudinal or concurrent relationships between anxiety and performance in young children. On the other hand, relationships between mathematics anxiety, other attitudes, and actual performance have been found in primary school children in a white South African community [22], in New Zealand [23], and in several studies in the United States ([24-27]).

It is thus possible that the relationships between attitudes and performance become clearer in the later primary years. The present study aimed to examine relationships between mathematical performance, mathematics anxiety, unhappiness over poor performance, liking for mathematics, and self-rating in mathematics in children of midprimary age (Grade 3; age 7-8) and later primary age (Grade 5; age 9 to $10)$.

On the basis of the earlier studies using a similar method $[20,21]$, it was predicted that mathematics performance would be related to liking mathematics and to self-rating of ability in the subject, but not to anxiety. It was also predicted, especially on the basis of Thomas and Dowker's [20] results that there would be specific independent relationships between liking mathematics and self-rating, and between anxiety and performance-related unhappiness, and that otherwise there would be little correlation between the attitude variables.

Another aim was to investigate changes between Grade 3 and Grade 5. It was predicted that older children might show more negative attitudes. We also aimed to look at whether the relationships between the different variables might change between Grade 3 and Grade 5. Although any such analysis would have to be tentative due to reduced numbers, it was predicted that the relationships between mathematics performance and other attitude variables, and especially between mathematics performance and self-rating, might not be noticeable at Grade 3 but might become significant at Grade 5. This prediction is based on the assumption that children's experiences of success and failure might influence their attitudes toward and confidence in mathematics, and that such experiences and their effects would become increasingly salient during the later primary school years.
The study also aimed to look at gender differences in mathematics performance and attitudes. Most current studies suggest that females do not perform lower in mathematics than males, but that they do tend to rate themselves lower, and to experience more anxiety $[28,29]$. The study aimed to investigate whether such gender differences would already be present in young children.

\section{Method}

2.1. Participants. The participants were 89 children taken from two state primary schools in Brentwood, Essex and one in Enfield, London. They were selected randomly from the third- and fifth-grade classes in these schools. These were nonselective schools with varied intakes, but situated in predominantly relatively middle-class areas. They included 44 children ( 21 boys and 23 girls) in Grade 3 and 45 children ( 21 boys and 24 girls) in Grade 5. The Grade 3 children had a mean age of 90.1 months (s.d. 3.48) and the Grade 5 children had a mean age of 112.39 months (s.d. 6.51).

2.2. Materials and Procedure. In order to measure their attitudes, children completed the Mathematics Attitudes and Anxiety Questionnaire [20,30]. The attitude questionnaire consists of 28 questions which focused on 7 areas of maths: maths in general, written sums, mental sums, easy maths, difficult maths, maths tests, and understanding the teacher. For each item, children were asked about their Self-rating ("How good are you?") on a scale consisting of ticks and crosses ("very good" to "very bad"); Liking for the items ("How much do you like it?") on a scale consisting of sweets and wasps ("like very much" to "hate very much"); Anxiety about them ("How worried would you feel?") on a scale of facial expressions based on Roger Hargreaves' "Mr. Men" picture-book characters Mr. Happy and Mr. Worry ("very relaxed" to "very worried"); Unhappiness at poor performance ("How unhappy would you feel if you did badly?") on a scale consisting of faces with frowning or happy faces ("very unhappy" to "very happy"). Possible rating scores for each item ranged from 1 to 5 , so the total possible scores on each scale ranged from 7 to 35 . Scores were calculated so that a higher score represented a more positive attitude. Thus, the Anxiety and Unhappiness scores represent relative freedom from Anxiety and Unhappiness. In places where there may be ambiguity, the paper will refer to "(Non-)Anxiety" and "(Non-)Unhappiness".

\section{Results}

Table 1 shows the BNS standard score and the attitude scores according to gender and school year.

\subsection{Effects of Gender and School Year on Mathematical} Performance and Attitude Scores. An ANOVA was carried out with Year Group (Grade 3 versus Grader 5) and Gender (Male versus Female) as the grouping factor, and BNS standard score and the attitude scores of Liking, Self-rating, Anxiety, and Unhappiness as the dependent variables. There 
TABLE 1: Maths performance and attitude scores by year group and gender.

\begin{tabular}{lcccccc}
\hline Year group & Gender & $\begin{array}{c}\text { BAS Basic Number } \\
\text { Skills standard score }\end{array}$ & Self-rating & Liking & (Non-)Anxiety & (Non-) Unhappiness \\
\hline Year 3 & Boys $(n=21)$ & $109.14(13.42)$ & $28.9(4.31)$ & $25.62(7.89)$ & $23.19(7.57)$ & $22.71(4.36)$ \\
& Girls $(n=23)$ & $112.65(12.8)$ & $27.26(4.46)$ & $24.43(5.56)$ & $23.0(6.33)$ & $21.04(5.23)$ \\
Total year 3 $(n=44)$ & & $110.98(13.07)$ & $28.04(4.42)$ & $25.0(6.72)$ & $23.09(6.87)$ & $21.84(4.86)$ \\
Year 5 & Boys $(n=21)$ & $120.52(13.61)$ & $29.05(4.76)$ & $24.62(8.52)$ & $23.05(4.86)$ & $21.00(4.86)$ \\
& Girls $(n=24)$ & $115.71(16.59)$ & $25.75(5.56)$ & $24.46(5.73)$ & $23.46(6.21)$ & $19.71(5.7)$ \\
Total year 5 $(n=45)$ & & $117.96(15.29)$ & $27.29(5.4)$ & $24.53(7.08)$ & $23.27(5.57)$ & $20.31(5.3)$ \\
& Total boys $(n=42)$ & $114.83(14.54)$ & $28.98(5.56)$ & $25.12(8.12)$ & $23.11(6.28)$ & $21.86(4.64)$ \\
Total $(n=89)$ & Total girls $(n=47)$ & $114.21(14.78)$ & $26.49(5.06)$ & $24.45(5.58)$ & $23.23(6.21)$ & $20.36(5.46)$ \\
\hline
\end{tabular}

Means are given with standard deviations in brackets.

was a significant effect of Year Group on basic number skills standard score $\left(F(1,85)=5.7 ; P=0.019 ; \eta P^{2}=0.063\right)$, indicating higher scores by the Grade 5 children. There was a significant effect of Gender on Self-rating $(F(1,85)=5.93$; $\left.P=0.018 ; \eta P^{2}=0.064\right)$, indicating higher self-rating by boys. No other effects were significant.

Because there were year group differences in BNS standard score, and because the year groups differed in both chronological age and school experience, an ANCOVA was then carried out including BNS standard score and chronological age in months (Age) as covariates. Again, Year Group (Grade 3 versus Grade 5) and Gender (Male versus Female) were the grouping factors, and BNS standard score and the attitude scores of Liking, Self-rating, Anxiety, and Unhappiness were the dependent variables. BNS standard score made a significant independent contribution to the variance in Self-rating $\left(F(1,83)=6.58 ; P=0.012 ; \eta P^{2}=\right.$ $0.073)$. Age made a significant independent contribution to Unhappiness $\left(F(1,83)=13.79 ; P<0.001 ; \eta P^{2}=0.143\right)$. After controlling the effects of the covariates, Gender still had a significant effect on Self-rating $(F(1,83)=5.64 ; P=$ $\left.0.02 ; \eta P^{2}=0.064\right)$. Year Group now had a significant effect on Unhappiness $\left(F(1,83)=16.38 ; P<0.001 ; \eta P^{2}=\right.$ $0.165)$.

3.2. Correlations between Attitudes and Mathematics Performance. Pearson correlation coefficients were obtained between the attitude scores of Liking, Self-rating, Anxiety and Unhappiness, BNS standard score, and age in months. These are shown in Table 2.

3.3. What Attitudes Predict Mathematical Performance? Table 3 shows entry-type linear regressions on each of the test variables, with the other variables as predictors. First, in order to investigate more directly the influence of attitudes on mathematical performance an entry-type linear regression was carried out with BNS standard score as the dependent variable, and Liking, Self-rating, (Non)Anxiety and (Non-)Unhappiness as the predictors. The only significant predictor was Self-rating.
Similar analyses were then carried out for each of the attitude variables, with BNS standard score and the other attitude variables as predictors.

Self-rating was predicted by all the other variables except (Non-)Anxiety; BNS standard score, (Non-)Unhappiness, and Liking were all significant independent predictors of Self-rating.

Liking was independently predicted by Self-rating and (Non-)Anxiety.

(Non-)Anxiety was independently predicted only by Liking, though (Non-) Unhappiness almost reached significance as a predictor $(P=0.058)$.

(Non-)Unhappiness was independently predicted only by Self-rating, though, as expected from the previous analysis, (Non-)Anxiety almost reached significance as a predictor.

The same analyses were then carried out separately for the group of third-grade children (Table 4) and the group of fifth-grade children (Table 5).

The findings for third-grade children are shown in Table 4.

None of the attitude variables predicted BNS standard score. Liking and (Non)-Unhappiness predicted Self-Rating. Self-Rating and (Non-)Anxiety predicted Liking. Self-Rating and Liking predicted (Non-)Anxiety. Self-rating predicted (Non-)Unhappiness.

The findings for fifth-grade children are shown in Table 5.

Self-rating was the only significant predictor of BNS standard score. Similarly, BNS standard score was the only significant predictor of Self-rating, (Non-)Anxiety was the only significant predictor of Liking, and Liking was the only significant predictor of (Non-)Anxiety. No predictor approached significance for (Non-)Unhappiness.

\section{Discussion}

The results support previous studies with primary age children in suggesting that attitudes to mathematics are generally positive in the primary age group. All attitude scores, except for (Non-)Unhappiness at poor performance, were considerably higher than the notional neutral score of 3 , though questions could be raised as to whether such a rating 
TABLE 2: Correlations between attitude scores, British abilities scales basic number skills standard score, and age in months.

\begin{tabular}{|c|c|c|c|c|c|c|}
\hline & Self rating & Liking & (Non-)Anxiety & (Non-)Unhappiness & $\begin{array}{c}\text { Basic Number } \\
\text { Skills: standard score }\end{array}$ & Age in months \\
\hline Self-rating & 1 & & & & & \\
\hline Liking & $0.264^{*}$ & 1 & & & & \\
\hline (Non-)Anxiety & 0.191 & $0.413^{* *}$ & 1 & & & \\
\hline (Non-)Unhappiness & $0.329^{* *}$ & 0.178 & $0.268^{*}$ & 1 & & \\
\hline Basic Number Skills: Standard score & $0.255^{*}$ & -0.1 & -0.069 & 0.021 & 1 & \\
\hline Age in months & -0.055 & -0.083 & 0.232 & 0.075 & 0.231 & 1 \\
\hline
\end{tabular}

$* P<0.05 * * P<0.01$.

TABLE 3: Entry-type multiple regressions on British abilities scales basic number skills standard score and the attitude variables: whole group.

\begin{tabular}{|c|c|c|c|c|c|}
\hline & $\begin{array}{l}\text { Regression on Basic } \\
\text { Number Skills } \\
\text { standard score }\end{array}$ & $\begin{array}{l}\text { Regression on } \\
\text { Self-rating }\end{array}$ & $\begin{array}{l}\text { Regression on } \\
\text { Liking }\end{array}$ & $\begin{array}{l}\text { Regression on } \\
\text { (non-)Anxiety }\end{array}$ & $\begin{array}{c}\text { Regression on } \\
\text { (non-)Unhappiness }\end{array}$ \\
\hline Degrees of freedom & 4 & 4 & 4 & 4 & 4 \\
\hline Residual & 84 & 84 & 84 & 84 & 84 \\
\hline$R^{2}$ & 0.106 & 0.484 & 0.226 & 0.211 & 0.159 \\
\hline$F$ & 2.502 & 6.414 & 6.148 & 5.631 & 3.96 \\
\hline$P$ & $0.048^{*}$ & $0.000 * *$ & $0.000 * *$ & $0.000^{* *}$ & $0.005^{* *}$ \\
\hline \multicolumn{6}{|l|}{ Predictors: } \\
\hline Basic number skills & - & & & & \\
\hline$\beta$ & - & 0.286 & -1.415 & 0.034 & -0.047 \\
\hline$t$ & - & 2.973 & -1.402 & -0.333 & -0.446 \\
\hline$P$ & - & $0.004^{* *}$ & 0.164 & 0.74 & 0.657 \\
\hline \multicolumn{6}{|l|}{ Self-rating } \\
\hline$\beta$ & 0.333 & - & 0.236 & 0.021 & 0.306 \\
\hline$t$ & 2.973 & - & 2.219 & 0.191 & 2.795 \\
\hline$P$ & $0.004^{* *}$ & - & $0.029^{*}$ & 0.849 & $0.006^{* *}$ \\
\hline Liking & & & - & & \\
\hline$\beta$ & -0.163 & 0.234 & - & 0.368 & 0.006 \\
\hline$t$ & -1.402 & 2.219 & - & 3.591 & 0.049 \\
\hline$P$ & 0.104 & $0.029^{*}$ & - & $0.001^{* *}$ & 0.961 \\
\hline \multicolumn{6}{|l|}{ (Non-)Anxiety } \\
\hline$\beta$ & 0.039 & 0.021 & 0.361 & - & 0.212 \\
\hline$t$ & 0.333 & 0.191 & 3.591 & - & 1.919 \\
\hline$P$ & 0.74 & 0.849 & $0.001^{* *}$ & - & 0.058 \\
\hline \multicolumn{6}{|l|}{ (Non-)Unhappiness } \\
\hline$\beta$ & -0.05 & 0.278 & 0.005 & 0.198 & - \\
\hline$t$ & -0.446 & 2.973 & 0.049 & 1.919 & - \\
\hline$P$ & 0.657 & $0.006^{* *}$ & 0.961 & 0.058 & - \\
\hline
\end{tabular}

${ }^{*} P<0.05 * * P<0.01$.

really does represent "neutrality". There was little difference in attitude between Grade 3 and Grade 5, contradicting the hypothesis that attitudes might deteriorate during this period.

In this particular group, the standard scores on a standardized arithmetic test were rather higher in Grade 5 than in Grade 3, giving rise to the possibility that group differences in mathematical attainment were masking deterioration in attitudes. However, even after controlling both arithmetic standard score and chronological age, there continued to be little effect of year group on attitude.

The exception was (non-) Unhappiness at poor performance, where the year group effect did become significant. However, this reflected a more positive attitude in Grade 5 
TABLE 4: Entry-type multiple regressions on British abilities scales basic number skills standard score and the attitude variables: Grade 3 alone.

\begin{tabular}{|c|c|c|c|c|c|}
\hline & $\begin{array}{l}\text { Regression on Basic } \\
\text { Number Skills } \\
\text { standard score }\end{array}$ & $\begin{array}{l}\text { Regression on } \\
\text { Self-rating }\end{array}$ & $\begin{array}{l}\text { Regression on } \\
\text { Liking }\end{array}$ & $\begin{array}{l}\text { Regression on } \\
\text { (non-)Anxiety }\end{array}$ & $\begin{array}{c}\text { Regression on } \\
\text { (non-)Unhappiness }\end{array}$ \\
\hline Degrees of freedom & 4 & 4 & 4 & 4 & 4 \\
\hline Residual & 39 & 39 & 39 & 39 & 39 \\
\hline$R^{2}$ & 0.01 & 0.318 & 0.281 & 0.204 & 0.264 \\
\hline$F$ & 0.095 & 4.552 & 3.45 & 2.503 & 3.496 \\
\hline$P$ & 0.984 & $0.004^{* *}$ & $0.017^{*}$ & 0.058 & $0.016^{*}$ \\
\hline \multicolumn{6}{|l|}{ Predictors: } \\
\hline \multicolumn{6}{|c|}{ Basic number skills: } \\
\hline$\beta$ & - & 0.019 & -0.016 & -0.011 & 0.08 \\
\hline$t$ & - & -0.145 & -0.112 & -0.074 & 0.583 \\
\hline$P$ & - & 0.885 & 0.911 & 0.942 & 0.563 \\
\hline \multicolumn{6}{|l|}{ Self-rating } \\
\hline$\beta$ & -0.028 & - & 0.414 & -0.054 & 0.417 \\
\hline$t$ & -0.145 & - & 2.035 & -0.314 & 2.74 \\
\hline$P$ & 0.885 & - & $0.01^{*}$ & 0.755 & $0.009^{* *}$ \\
\hline \multicolumn{6}{|l|}{ Liking } \\
\hline$\beta$ & -0.021 & 0.382 & - & 0.322 & -0.121 \\
\hline$t$ & -0.112 & 2.707 & - & 2.035 & -0.764 \\
\hline$P$ & 0.911 & $0.01^{*}$ & - & $0.049^{*}$ & 0.449 \\
\hline \multicolumn{6}{|l|}{ (Non-)Anxiety } \\
\hline$\beta$ & -0.013 & -0.047 & 0.298 & - & 0.288 \\
\hline$t$ & -0.074 & -0.314 & 2.035 & - & 1.957 \\
\hline$P$ & 0.942 & 0.785 & $0.049^{*}$ & - & 0.058 \\
\hline \multicolumn{6}{|c|}{ (Non-)Unhappiness } \\
\hline$\beta$ & 0.108 & 0.387 & -0.122 & 0.311 & - \\
\hline$t$ & 0.583 & 2.74 & -0.764 & 1.957 & - \\
\hline$P$ & 0.563 & $0.009^{* *}$ & 0.449 & 0.058 & - \\
\hline
\end{tabular}

${ }^{*} P<0.05{ }^{* *} P<0.01$.

than Grade 3 children. Age was also separately significant as a covariate, and it correlated negatively with this attitude variable. As Unhappiness was not significantly related to either age or year group when they were considered separately, these results should be taken with caution at this point, but attempts should be made to replicate them in future studies.

It should be noted that there may be more ambiguity about the positive or negative nature of Unhappiness at poor performance than over the other attitudes. Certainly, a high level of unhappiness at poor performance is a negative attitude, but at the end of the scale where children are relatively free of such unhappiness, individual differences in scores may be more reflective of a preference for performing well, arguably a positive attitude. Perhaps the somewhat puzzling results here could reflect this ambiguity.

Correlational analyses indicate little relationship between chronological age and the attitude variables, supporting the findings with regard to year group effects. As predicted, they support the earlier results of [10] and Krinzinger et al. [21], in showing no consistent relationship between mathematics
Anxiety and performance among primary school children. There was, however, a significant relationship between Anxiety and Liking for mathematics; not surprisingly, a Liking for mathematics was strongly associated with a freedom from Anxiety.

The only attitude variable that correlated significantly with actual performance was Self-rating. Those who rated themselves higher at maths performed better. Self-rating appeared indeed to be the only variable that was strongly related to all the other variables. As well as being related to actual performance, it was related to Liking for maths and to freedom from Anxiety. After controlling for other variables in regression analyses, it was also related to freedom from performance-related Unhappiness.

Somewhat unexpectedly, there was no significant relationship between Liking for maths and actual performance, though Liking for maths was significantly related to other attitude variables.

It had been predicted that Anxiety and Unhappiness at poor performance might be strongly and independently 
TABLE 5: Entry-type multiple regressions on British abilities scales basic number skills standard score and the attitude variables: Grade 5 alone.

\begin{tabular}{|c|c|c|c|c|c|}
\hline & $\begin{array}{c}\text { Regression on basic } \\
\text { number skills } \\
\text { standard score }\end{array}$ & $\begin{array}{l}\text { Regression on } \\
\text { self-rating }\end{array}$ & $\begin{array}{l}\text { Regression on } \\
\text { liking }\end{array}$ & $\begin{array}{l}\text { Regression on } \\
\text { (non)anxiety }\end{array}$ & $\begin{array}{c}\text { Regression on } \\
\text { (non)unhappiness }\end{array}$ \\
\hline Degrees of freedom & 4 & 4 & 4 & 4 & 4 \\
\hline Residual & 40 & 40 & 40 & 40 & 40 \\
\hline$R^{2}$ & 0.31 & 0.337 & 0.275 & 0.281 & 0.103 \\
\hline$F$ & 4.495 & 5.084 & 3.794 & 3.903 & 1.154 \\
\hline$P$ & $0.004^{* *}$ & $0.002^{* *}$ & $0.01^{*}$ & $0.009^{* *}$ & 0.346 \\
\hline \multicolumn{6}{|l|}{ Predictors: } \\
\hline Basic number skills & - & & & & \\
\hline$\beta$ & - & 0.522 & -0.157 & -0.15 & -0.05 \\
\hline$t$ & - & 3.983 & -0.979 & -0.939 & -0.277 \\
\hline$P$ & - & $0.000^{* *}$ & 0.334 & 0.353 & 0.784 \\
\hline \multicolumn{6}{|l|}{ Self-rating } \\
\hline$\beta$ & -0.028 & - & 0.135 & 0.133 & 0.243 \\
\hline$t$ & -0.145 & - & 0.821 & 0.813 & 1.354 \\
\hline$P$ & 0.885 & - & 0.416 & 0.421 & 0.183 \\
\hline \multicolumn{6}{|l|}{ Liking } \\
\hline$\beta$ & -0.021 & 0.123 & - & 0.436 & 0.087 \\
\hline$t$ & -0.112 & 0.821 & - & 3.082 & 0.498 \\
\hline$P$ & 0.911 & 0.416 & - & $0.004^{* *}$ & 0.621 \\
\hline \multicolumn{6}{|l|}{ (Non)anxiety } \\
\hline$\beta$ & -0.013 & 0.122 & 0.44 & - & 0.129 \\
\hline$t$ & -0.074 & 0.813 & 3.082 & - & 0.735 \\
\hline$P$ & 0.942 & 0.421 & $0.004^{* *}$ & - & 0.467 \\
\hline \multicolumn{6}{|l|}{ (Non)unhappiness } \\
\hline$\beta$ & 0.108 & 0.18 & 0.021 & 0.103 & - \\
\hline$t$ & 0.583 & 1.354 & 0.498 & 0.735 & - \\
\hline$P$ & 0.563 & 0.183 & 0.621 & 0.467 & - \\
\hline
\end{tabular}

${ }^{*} P<0.05 * * P<0.01$

correlated with one another but not with the other attitude variables, and that Liking for maths and Self-rating might be strongly and independently correlated with one another but not with the other attitude variables. This prediction was not entirely borne out. Self-rating and Liking for maths did show an independent relationship, but Self-rating was also independently related to the other attitude variables. Liking for maths was correlated with Anxiety as well as Selfrating. There was only a weak relationship between Anxiety and performance Unhappiness, and each correlated more strongly with other factors: Anxiety with Liking for maths, and performance Unhappiness with Self-rating.

The results of separate regression analyses for different year groups suggest that, although there are few age or year group differences in the attitude scores themselves, there may be some differences in the relationships between the variables. A great deal of caution is needed in interpreting these results, because of the reduced sample sizes in these analyses, resulting in relatively low statistical power. It is possible that there were some small effects that would only have become obvious in larger samples. However, the results do support the hypothesis that the relationship between selfrating and actual performance may develop between Grade 3 and Grade 5. There was no relationship between the two variables in Grade 3 children. In Grade 3, none of the attitude variables predicted mathematical performance, and Self-rating was predicted by Liking for maths and freedom from Anxiety, but not by performance. In Grade 5, by contrast, there was a very strong and specific relationship between Self-rating and actual performance. This finding may suggest that children become more aware of their mathematical performance in relation to that of their peers as they become older, either because of generally greater self-awareness, or because of greater experience of tests and teacher assessments. Alternatively, or additionally, it may be that children's self-assessment has an increasing influence on their motivation, and thereby on their performance, as they get older.

The only significant gender difference was in self-rating, where boys rated themselves higher than girls did. There 
were no gender differences in actual performance or in other attitudes. This supports findings from previous studies that indicate that males tend to rate themselves higher than females in mathematics, although at least in recent studies the genders usually perform similarly. Future research should investigate whether this finding is specific to self-rating in mathematics, where it may reflect existing stereotypes about the subject, or whether it might indicate generally higher selfratings by boys in other subjects as well.

One key limitation of this study is of course that the sample is relatively small. It is important for future studies to extend both the number and the range of the sample. For example, the children in the sample were attending schools in relatively middle-class catchment areas and, perhaps linked to this fact, were generally performing at somewhat above average levels in mathematics. The mean standard score on the basic number skills test was 114.51, as compared with an assumed population mean standard score of 100. It is possible that a lower-attaining group, or one including a higher proportion of children from low-SES backgrounds, might show more negative attitudes and/or stronger relationships between attitudes and performance.

Also, it is important to carry out cross-cultural comparisons. This study aligns with most similar non-American studies (e.g., $[17,21])$, in suggesting that younger children do not show a significant relationship between mathematics anxiety and actual mathematical performance, but, as indicated in the Introduction, most American studies have given contrasting results (e.g., [24-26]). It would be interesting to investigate whether there is some difference in cultural attitudes or in methods of mathematics education that contributes to this disparity. It would also be desirable to investigate young children's attitudes to mathematics in a wider variety of cultures.

It could be argued that a questionnaire measure is not ideal as a sole measure of attitudes in young children, or perhaps in any group. In future studies, it would be desirable to include other measures: for example implicit attitude tests [31], behavioural measures such as children's responses when given a choice between activities with and without mathematical content, and perhaps physiological indicators of anxiety. It would also be desirable to use a wider variety of mathematics tests, in particular, to use tests of mental as well as written arithmetic, as the former is more likely to be affected by the increased load that anxiety may place on working memory $([5,25])$.

Despite such potential limitations, the study yields some important conclusions. Young children appear to show relatively positive attitudes to mathematics, though a larger sample of different ages would be needed to confirm this. They show little relationship between mathematics anxiety and mathematical performance, but they do show a relationship between self-rating and mathematical performance, which seems to develop during the later primary years. There are also significant relationships between self-rating and other attitudes. It is thus arguable that self-rating, rather than mathematics anxiety, is the key factor in the primary school age group, and that perhaps researchers on younger children's attitudes to mathematics should focus more on self-rating.

\section{References}

[1] M. Baloğlu and R. Koçak, "A multivariate investigation of the differences in mathematics anxiety," Personality and Individual Differences, vol. 40, no. 7, pp. 1325-1335, 2006.

[2] R. Hembree, "The nature, effects, and relief of mathematics anxiety," Journal For Research in Mathematics Education, vol. 21, no. 1, pp. 33-46, 1990.

[3] H. Miller and J. Bichsel, "Anxiety, working memory, gender, and math performance," Personality and Individual Differences, vol. 37, no. 3, pp. 591-606, 2004.

[4] M. H. Ashcraft, "Math anxiety: personal, educational, and cognitive consequences," Current Directions in Psychological Science, vol. 11, no. 5, pp. 181-185, 2002.

[5] M. H. Ashcraft and J. A. Krause, "Working memory, math performance, and math anxiety," Psychonomic Bulletin and Review, vol. 14, no. 2, pp. 243-248, 2007.

[6] E. A. Maloney and S. Beilock, "Math anxiety: who has it, why it develops, and how to guard against it," Trends in Cognitive Sciences, vol. 16, no. 8, pp. 404-406, 2012.

[7] J. Evans, Adults' Mathematical Thinking and Emotions: A Study of Numerate Practices, Routledge, London, UK, 2000.

[8] V. A. Krutetskii, The Psychology of Mathematical Abilities in Schoolchildren, University of Chicago Press, London, UK, 1976.

[9] P. Blatchford, "Pupils' views on school work and school from 7 to 16 years," Research Papers in Education, vol. 11, no. 3, pp. 263-288, 1996.

[10] A. Dowker, Individual Differences in Arithmetic: Implications for Psychology, Neuroscience and Education, Psychology Press, New York, NY, USA, 2005.

[11] B. Tizard, P. Blatchford, J. Burke, C. Farquhar, and I. F. Plewis, Young Children at School in the Inner City, Erlbaum, London, UK, 1988.

[12] P. Mortimore, School Matters: The Junior Years, Open Books, Wells, UK, 1988.

[13] A. Wigfield and J. L. Meece, "Math anxiety in elementary and secondary school students," Journal of Educational Psychology, vol. 80, no. 2, pp. 210-216, 1988.

[14] M. J. Gierl and J. Bisanz, "Anxieties and attitudes related to mathematics in grades 3 and 6," Journal of Experimental Education, vol. 63, no. 2, pp. 139-158, 1995.

[15] L. R. Aiken, "Two scale of attitude toward mathematics," Journal For Research in Mathematics Education, vol. 5, no. 2, pp. 67-71, 1974.

[16] H. Z. Ho, D. Senturk, A. G. Lam et al., "The affective and cognitive dimensions of math anxiety: a cross-national study," Journal for Research in Mathematics Education, vol. 31, no. 3, pp. 362-379, 2000.

[17] X. Ma and N. Kishor, "Assessing the relationship between attitude toward mathematics and achievement in mathematics: a meta-analysis," Journal for Research in Mathematics Education, vol. 28, no. 1, pp. 26-47, 1997.

[18] E. A. Maloney, D. Ansari, and J. A. Fugelsang, "The effect of mathematics anxiety on the processing of numerical magnitude," Quarterly Journal of Experimental Psychology, vol. 64, no. 1, pp. 10-16, 2011. 
[19] M. Cain-Caston, "Parent and student attitudes toward mathematics as they relate to third grade mathematics achievement," Journal of Instructional Psychology, vol. 20, no. 2, pp. 96-101, 1993.

[20] G. Thomas and A. Dowker, "Mathematics anxiety and related factors in young children," in Proceedings of the British Psychological Society Developmental Section Conference, Bristol, UK, September 2000.

[21] H. Krinzinger, L. Kaufmann, and K. Willmes, "Math anxiety and math ability in early primary school years," Journal of Psychoeducational Assessment, vol. 27, no. 3, pp. 206-225, 2009.

[22] K. Newstead, "Aspects of children's mathematics anxiety," Educational Studies in Mathematics, vol. 36, no. 1, pp. 53-71, 1998.

[23] J. Young-Loveridge, The Development of Children's Number Concepts from Ages Five to Nine, Early Mathematics Learning Project, Education Department, University of Waikato, Hamilton, New Zealand, 1991.

[24] J. A. Dossey, I. V. S. Mullis, M. M. Lindquist, and D. L. Chambers, The Mathematics Report Card. Are We Measuring up? Trends and Achievement Based on the 1986 National Assessment, Educational Testing Service, Princeton, NJ, USA, 1988.

[25] G. Ramirez, E. A. Gunderson, S. C. Levine, and S. L. Beilock, "Math anxiety, working memory and math achievement in early elementary school," Journal of Cognition and Development. In press.

[26] S. S. Wu, M. Barth, H. Amin, V. Malcarne, and M. Vinod, "Math anxiety in second and third graders and its relation to mathematical achievement," Frontiers in Developmental Psychology, vol. 3, p. 162, 2012.

[27] C. B. Young, S. S. Wu, and V. Menod, "The neurodevelopmental basis of math anxiety," Psychological Science, vol. 23, pp. 492-501, 2012.

[28] A. Devine, K. Fawcett, D. Szucs, and A. Dowker, "Gender differences in mathematics anxiety and the relation to mathematics performance while controlling for test anxiety," Behavioral and Brain Functions, vol. 8, article 33, 2012.

[29] N. M. Else-Quest, J. S. Hyde, and M. C. Linn, "Crossnational patterns of gender differences in mathematics: a meta-analysis," Psychological Bulletin, vol. 136, no. 1, pp. 103$127,2010$.

[30] H. Krinzinger, L. Kaufmann, A. Dowker et al., "Deutschsprachige Version des Fragebogens für Rechenangst (FRA) für 6- bis 9-jährige Kinder," Zeitschrift fur Kinder und Jugendpsychiatrie und Psychotherapie, vol. 35, no. 5, pp. 341-351, 2007.

[31] O. Rubinsten and R. Tannock, "Mathematics anxiety in children with developmental dyscalculia," Behavioral and Brain Functions, vol. 6, article 46, 2010. 


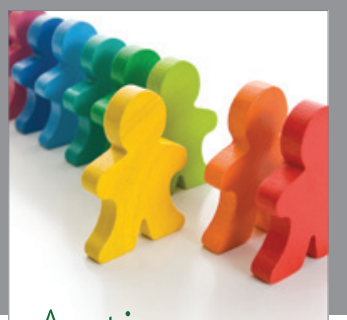

Autism

Research and Treatment
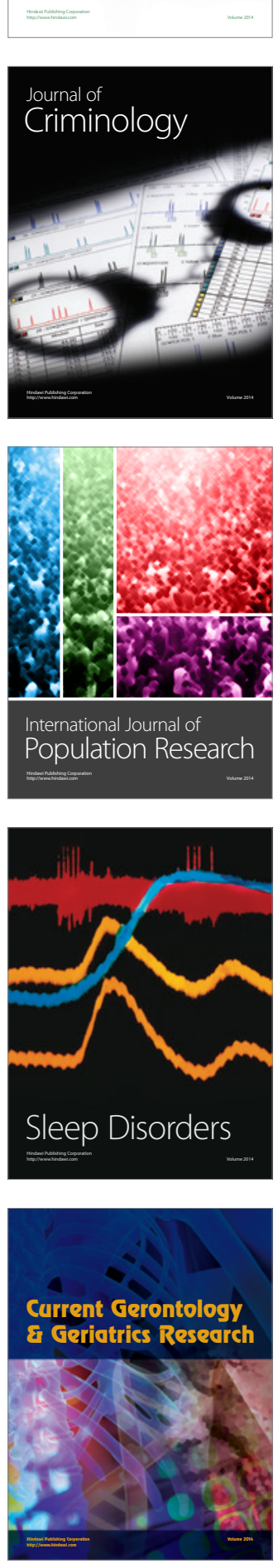
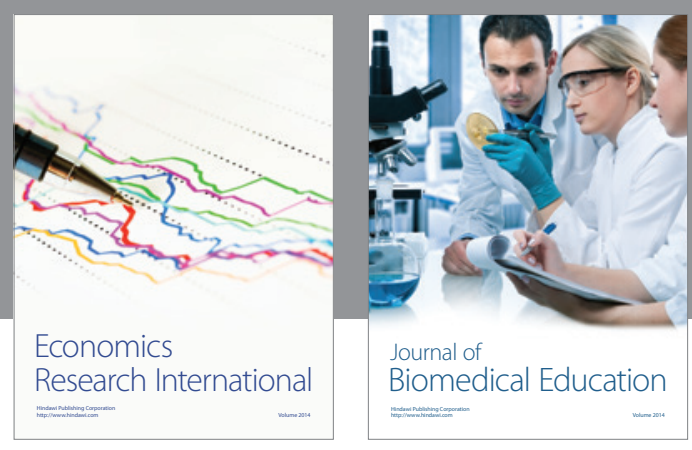

Journal of

Biomedical Education

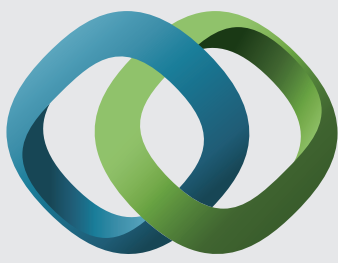

\section{Hindawi}

Submit your manuscripts at

http://www.hindawi.com
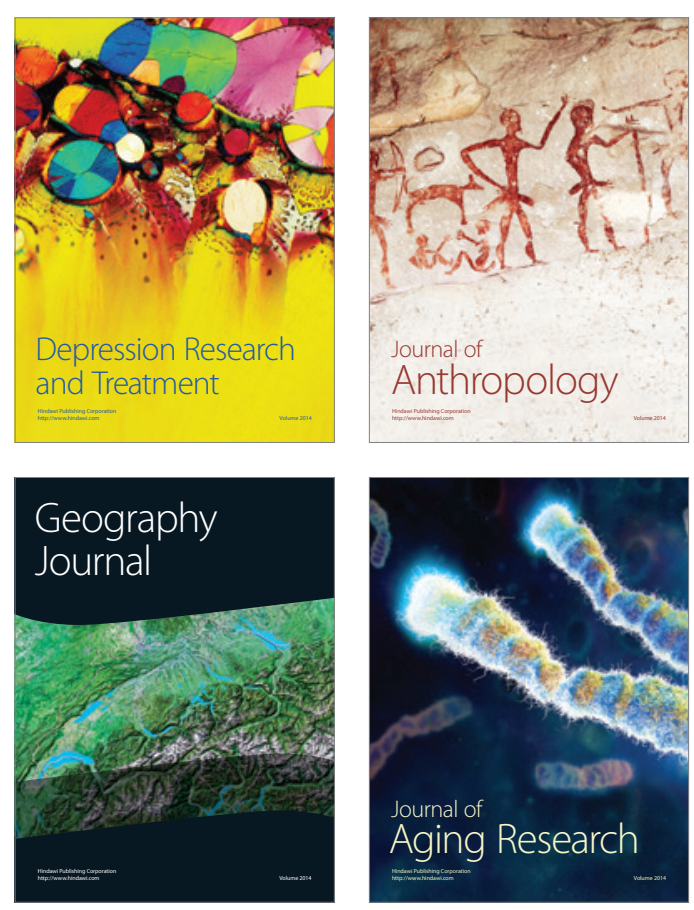

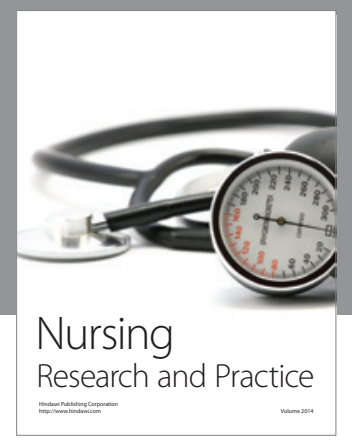

Nursing

Research and Practice

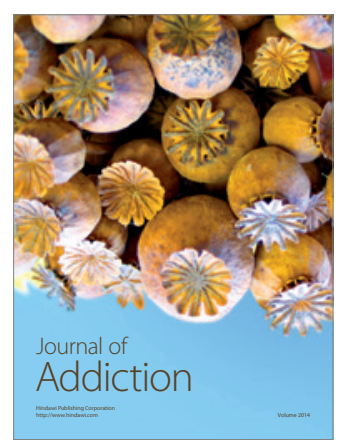

Child Development

Research

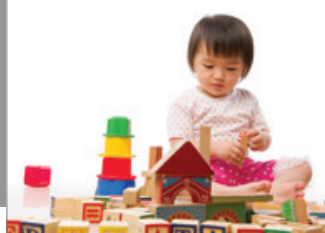

迥
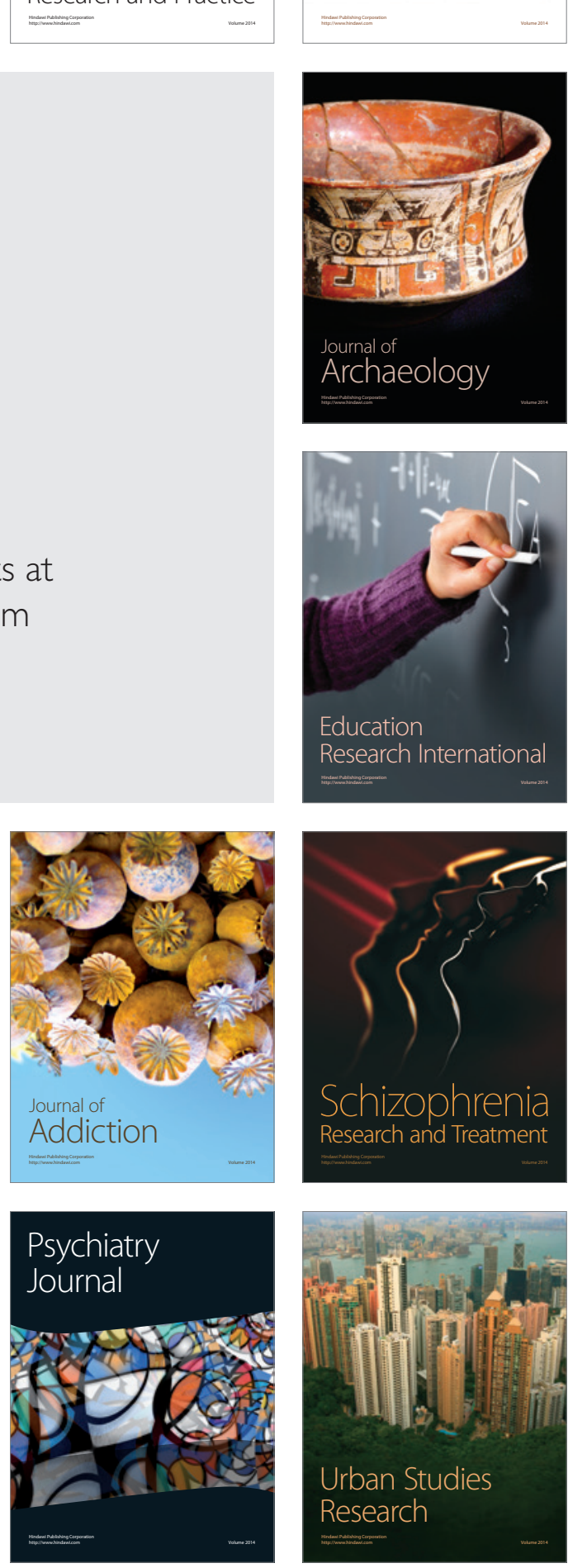